\title{
Obstructive jaundice caused by a giant liver hemangioma with Kasabach-Merritt syndrome: a case report
}

\author{
Takuya Yano, Tsuyoshi Kobayashi", Shintaro Kuroda, Hironobu Amano, Hirotaka Tashiro and Hideki Ohdan
}

\begin{abstract}
Hemangioma is the most common benign tumor of the liver. Liver hemangioma $(\mathrm{LH})$ usually remains asymptomatic, but the most common symptoms associated with LH are abdominal pain and discomfort. LH is an uncommon cause of bile duct dilatation and obstructive jaundice. An 83-year-old Japanese woman who received hemodialysis at another hospital was referred to our hospital because of abnormal liver function and obstructive jaundice. Abdominal computed tomography and magnetic resonance imaging revealed a 13-cm tumor in liver segments IV-V and intrahepatic bile duct dilatation. Endoscopic retrograde cholangiopancreatography revealed extrinsic compression of the bile duct at the hepatic hilar region. Laboratory tests showed that the patient had low platelet counts and low fibrinogen levels. Because the patient had hyperbilirubinemia and Kasabach-Merritt syndrome, we performed a segmentectomy of liver segments IV and V. Histological examination showed hemangioma of the liver. The patient's thrombocytopenia and coagulopathy improved immediately after surgery. In conclusion, LH is a very rare cause of obstructive jaundice. LH has the potential to compress the bile duct and cause obstructive jaundice.
\end{abstract}

Keywords: Hemangioma; Obstructive jaundice; Biliary stricture; Kasabach-Merritt syndrome

\section{Background}

Liver hemangioma $(\mathrm{LH})$ is the most common benign tumor arising in the liver, with an estimated prevalence of 0.4 to $7.3 \%$ in the general population $[1,2]$. Most LHs are reported to be asymptomatic. However, in patients undergoing surgery for hemangioma, $65 \%$ of hemangiomas are symptomatic, with abdominal pain or discomfort being the most common symptoms [3]. The typical hemangioma is relatively small $(<2 \mathrm{~cm})$, but larger $\mathrm{LH}$ sometimes are observed, some measuring up to $30 \mathrm{~cm}$ in diameter. Biliary obstruction is a very rare manifestation of hemangioma.

We present a case with obstructive jaundice due to LH coexisting with Kasabach-Merritt syndrome, together with a discussion of the related medical literature.

\footnotetext{
*Correspondence: tsukoba@hiroshima-u.ac.jp

Department of Gastroenterological and Transplant Surgery, Applied Life Sciences, Institute of Biomedical \& Health Sciences, Hiroshima University, 1-2-3 Kasumi, Minami-ku, Hiroshima 734-8551, Japan
}

\section{Case presentation}

An 83-year-old woman with diabetes mellitus, hypertension, and spinal canal stenosis who was undergoing hemodialysis for chronic renal failure was admitted to another hospital, with itching as the chief complaint. She had notable hyperbilirubinemia (total bilirubin (T-Bil), $4.6 \mathrm{mg} /$ $\mathrm{dl}$; direct bilirubin (D-Bil), $3.7 \mathrm{mg} / \mathrm{dl}$; alkaline phosphatase (ALP), $1333 \mathrm{U} / \mathrm{L}$; gamma glutamyl transpeptidase ( $\gamma$-GTP), $350 \mathrm{U} / \mathrm{L}$ ) in blood examination. Abdominal echography examination revealed intrahepatic bile duct dilatation and computed tomography (CT) showed a 13- $\mathrm{cm}$ mass in the right lobe of the liver. Endoscopic retrograde cholangiopancreatography (ERCP) revealed extrinsic compression of the bile duct at the hepatic hilar region.

To improve the jaundice, endoscopic nasobiliary drainage was performed and yielded gradual improvements in the jaundice. At the same time, biliary cytology was performed. The architecture was disturbed, characterized by variation in internuclear distances and dyskaryosis. Therefore, the liver tumor was diagnosed as suspicious for malignancy.

\section{勿 Springer}


The patient was transferred to our hospital for hepatic tumor therapy.

Laboratory tests of biliary enzymes showed an improvement (T-Bil, $1.1 \mathrm{mg} / \mathrm{dl}$; D-Bil, $0.6 \mathrm{mg} / \mathrm{dl}$; ALP, 600 U/L; $\gamma$-GTP, $57 \mathrm{U} / \mathrm{L}$ ) but revealed blood coagulopathy (platelet count, $9.6 \times 10^{3}$ per cubic millimeter; fibrinogen, $122.5 \mathrm{mg} / \mathrm{dl}$; fibrinogen and fibrin degradation products (FDP), $200 \mu \mathrm{g} / \mathrm{ml}$; D-dimer, $88.8 \mu \mathrm{g} / \mathrm{ml}$ ).

CT revealed a huge mass without enhancement, with a diameter of $13 \mathrm{~cm}$, and clear boundaries in the anterior and medial sections of the liver. The tumor caused compression of a bile duct in the hepatic hilar region and intrahepatic bile ducts were dilated (Fig. 1a).

Previous CT scans 5 years ago at our hospital showed that the size of a tumor at the same locus was $28 \mathrm{~mm}$ (Fig. 1b).

A low signal on the T1-weighted image and a slightly high signal on the T2-weighted image were observed by using magnetic resonance imaging (MRI) (Fig. 1c).

A stricture of approximately $2 \mathrm{~cm}$ was observed in the common bile duct on ERCP and suspected to be a result of compression from the outside wall, causing partial expansion of a right lobe bile duct and high expansion of the left lobe bile duct (Fig. 1d).
The preoperative diagnosis was suspected to be cavernous hemangioma, but differential diagnosis suggested hemangioendothelioma and hepatic echinococcosis. Because of the malignant potential of the tumor and the coexistence of Kasabach-Merritt syndrome, surgery was performed.

Operative findings macroscopically showed a normal liver with a soft and multilocular 13-cm tumor localized in Segment IV-Segment V. A segmentectomy of the liver segments IV and V was performed with resection of the middle hepatic vein. We confirmed that a stricture of a bilateral hepatic duct was removed using intraoperative cholangiography. The intraoperative bleeding volume was $1930 \mathrm{ml}$. She received transfusion of 4 units of red blood cell transfusion, 5 units of fresh frozen plasma, and 10 units of platelet transfusion during the intraoperative period. She did not need transfusion before and after operation.

Pathology revealed that the tumor was composed of cavernous vascular spaces of varying sizes lined by a single layer of flat endothelium. There was focal stromal fibrosis, calcification, and hyalinization (Fig. 2). Our final diagnosis of the patient was cavernous hemangioma of the liver.
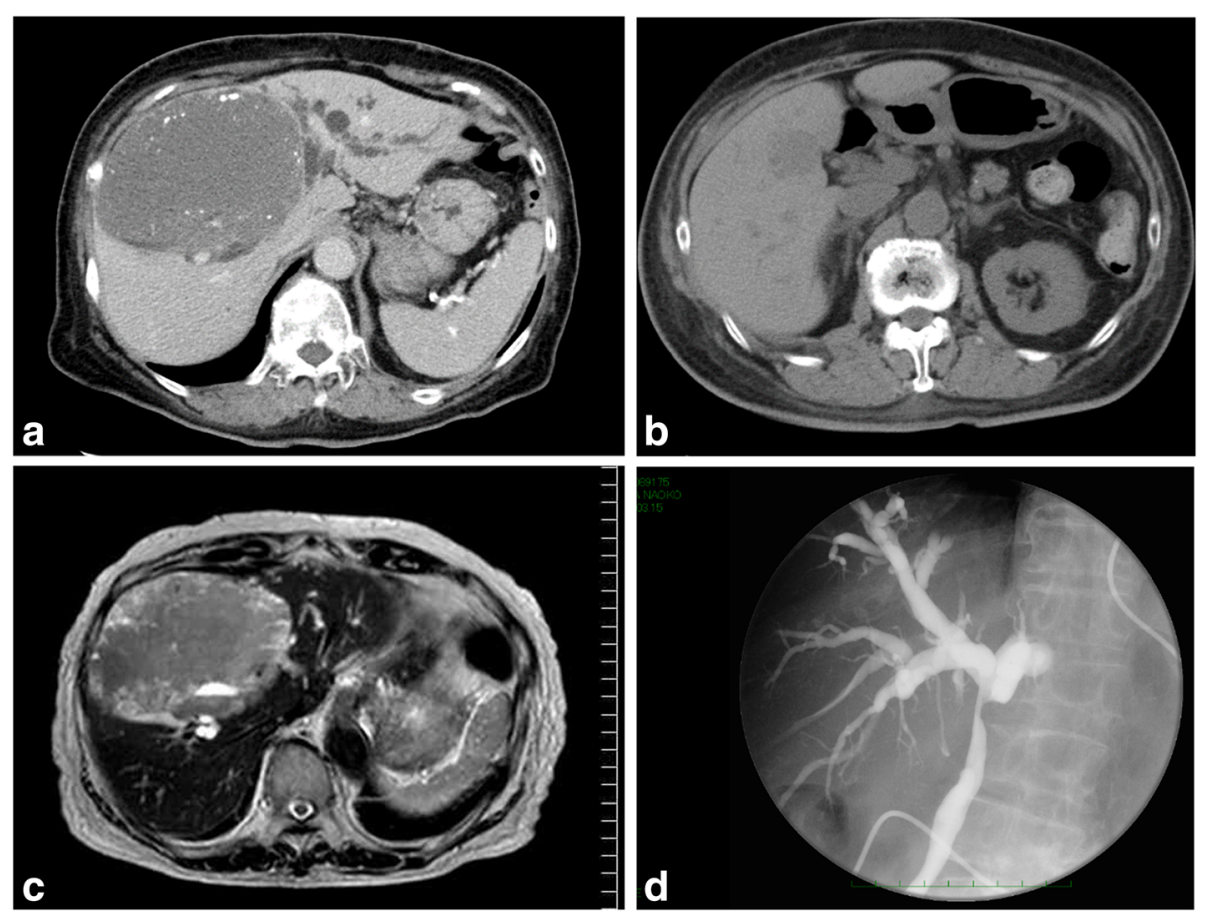

Fig. 1 Radiological findings. a Computed tomography $(C T)$ scan of the abdomen showing a well-demarcated liver mass consistent with hemangioma in the anterior segment of the right hepatic lobe to segment IV. The tumor pressed a bile duct in the hepatic portal region, causing an intrahepatic bile duct to expand. $\mathbf{b}$ A CT scan performed 5 years prior to the study shows a low-density tumor with a diameter of $28 \mathrm{~mm}$ in the right lobe. $\mathbf{c}$ The size of the tumor was shown to be $13 \mathrm{~cm}$ in diameter in magnetic resonance imaging, with a clearly demarcated border and a heterogeneous signal on T2-weighted images. The tumor had a fluid-fluid level at the tumor margins. $\mathbf{d}$ A stricture of approximately $2 \mathrm{~cm}$ in length in the common bile duct was observed via endoscopic retrograde cholangiography and suspected to be a result of compression from the outside wall. This caused partial expansion of a right lobe bile duct and high expansion of the left lobe bile duct 

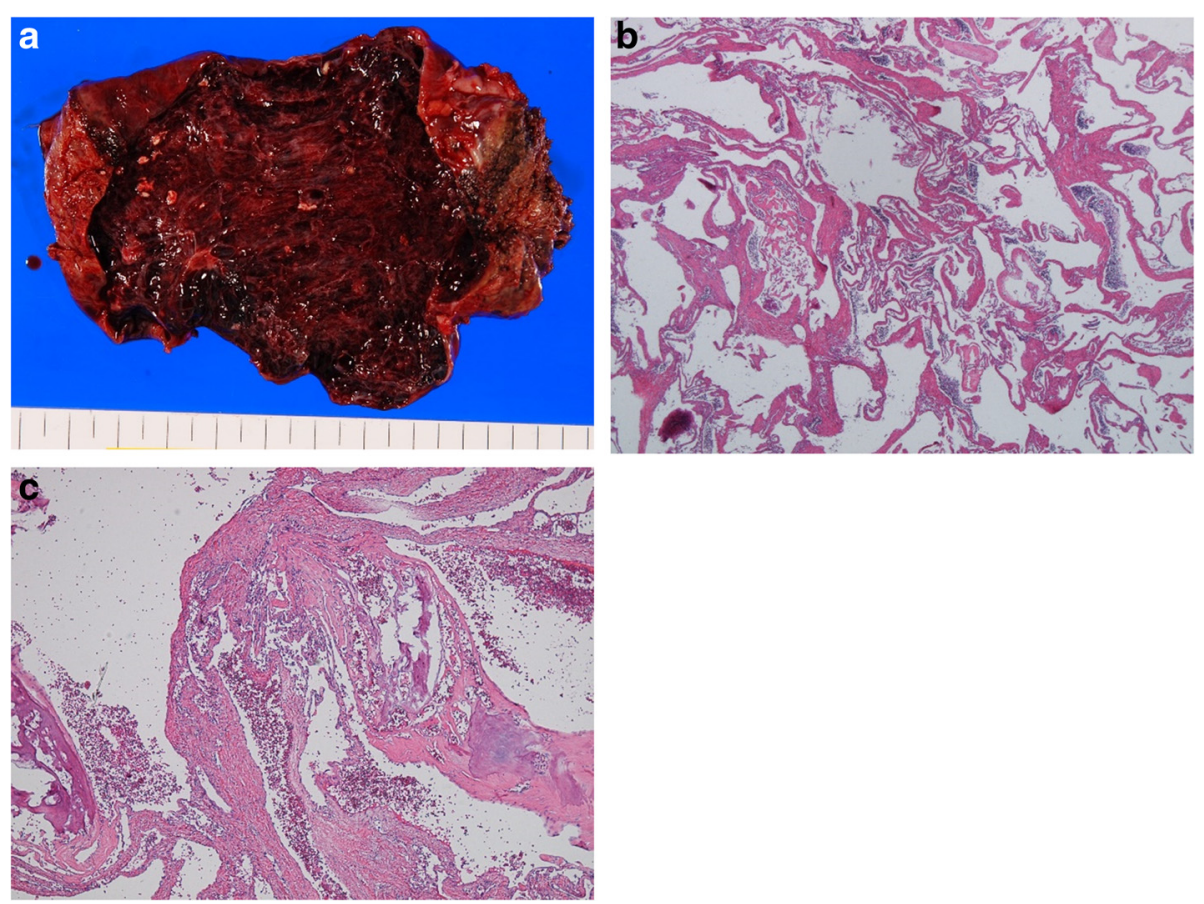

Fig. 2 Gross and histological findings. a The tumor was wine colored and elastic. b The tumor was composed of blood-filled spaces lined by a single layer of endothelial cells without smooth muscle (H\&E staining, objective; $\times 40$ ). c Fibrotic, hyalinized, and calcified lesions were observed (H\&E staining, objective; $\times 40)$

Postoperative cholangiography did not show a biliary stricture. After surgical resection of the hemangioma, blood coagulopathy improved (Fig. 3) (platelet count, 183 per cubic millimeter; fibrinogen, $328.1 \mathrm{mg} / \mathrm{dl}$, FDP, $24.4 \mu \mathrm{g} / \mathrm{ml}$; D-dimer, $12.6 \mu \mathrm{g} / \mathrm{ml})$, and the patient was able to resolve her thrombocytopenia and coagulopathy.

\section{Discussion}

Most patients with cavernous hemangioma are asymptomatic but a minority present with abdominal pain or abdominal distension. Hemangiomas have been identified at autopsy in up to $7 \%$ of patients and are more common in women than in men [1]. Lesions are usually dark red and

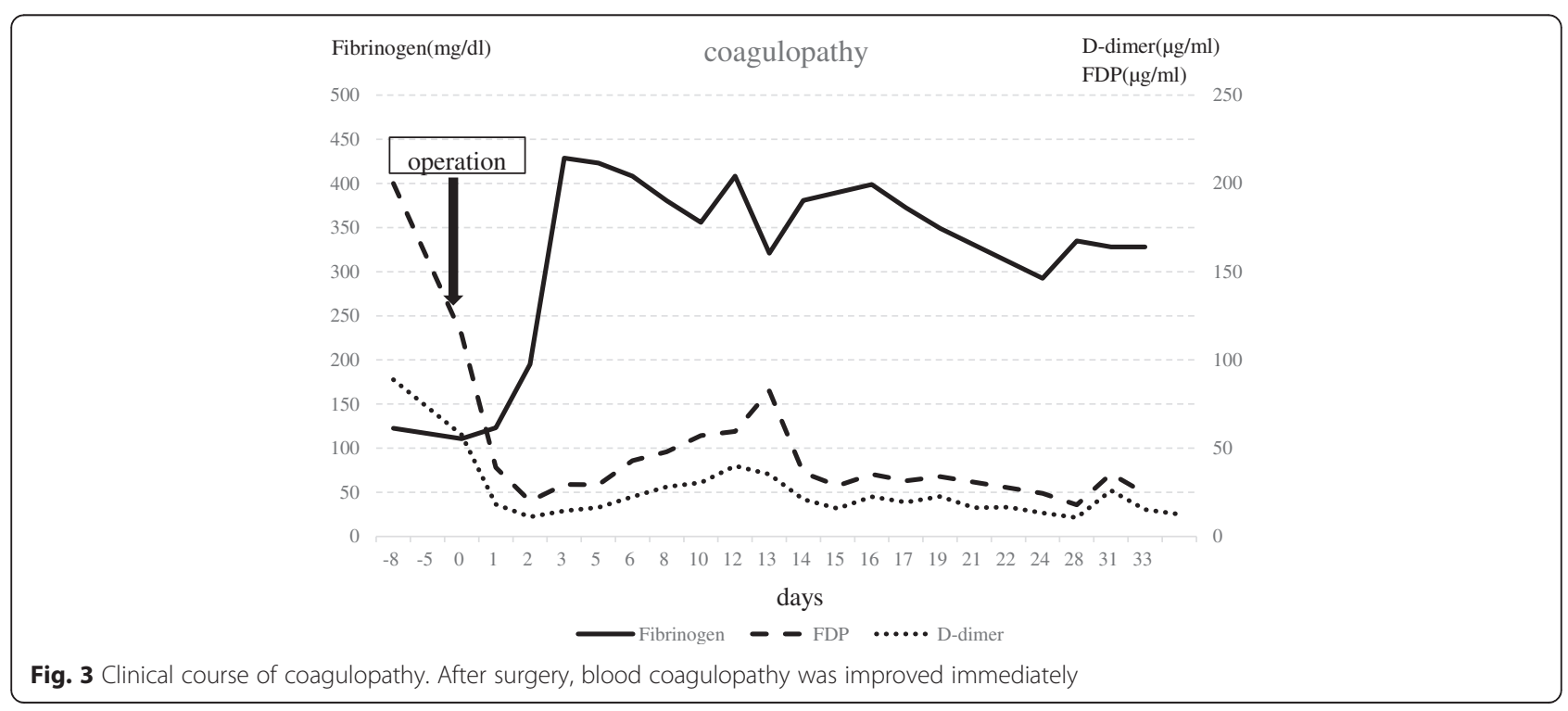


well circumscribed, but the macroscopic appearance can vary because of thrombosis, fibrosis, and calcification. Histologically, cavernous hemangiomas are composed of blood-filled spaces lined by a single layer of endothelial cells and supported by a basement membrane. Fibrosis is variable but may involve the entire lesion (sclerosed hemangioma). Rare complications include spontaneous rupture, traumatic rupture, portal hypertension, and coagulopathy. The identification of hemangiomas using radiological imaging can be difficult, but investigations with relatively high sensitivity and specificity include MRI scans, contrast-enhanced CT, and nuclear medicine scans using labeled red cells.

Dilatation of the intrahepatic bile ducts can occur as a result of either compression or tumor spread in patients with malignant liver tumor, such as (1) tumor spread to and sheathing of the bile ducts in cholangiocarcinomas, (2) growing cast within the bile ducts in hepatocellular carcinomas, and (3) metastatic infiltration of the bile ducts, particularly in colon adenocarcinoma [4]. Bile duct dilatation can be an important indicator of malignant liver tumors. In contrast, benign liver tumors are not considered to be a cause of bile duct dilatation, even if they are very large $[5,6]$.

Until now, only two resected adult cases with obstructive jaundice by cavernous hemangioma have been reported in the English literature (Table 1) [7, 8]. Including this case, all cases were observed in women with an age of 31-83 years. The tumor was $13-20 \mathrm{~cm}$ in diameter. One report was of a biliary stricture caused by a hepatic cyst [6]. The locus of the hepatic cysts was an existing case close to the hilum. Even in benign cases, other structures may show the presence of biliary stricture in lesions close to the hilum [9]. Two hemangioma cases causing the biliary stricture were close to the hilum similarly. In our case, the tumor was located in segment IV, close to the hilum. If hemangioma is close to the hilum, there is a possibility that hemangioma can cause biliary stricture regardless of tumor size.

The incidence of Kasabach-Merritt syndrome in LH is around $1.7 \%$ [3], but Kasabach-Merritt syndrome is a serious complication characterized by a very large hemangioma with thrombocytopenia and consumption coagulopathy due to endothelial defects within the hemangioma. In our case, according to $\mathrm{CT}$, the hemangioma had enlarged over 5 years. The enlarging of the hemangioma from 5 years ago caused Kasabach-Meritt syndrome, and the hemangioma, to reach hepatic portal region. We consider that the hemangioma which was close to hilum induced bile duct stricture. There is another speculation about Kasabach-Meritt syndrome and bile duct stricture. Consumptive coagulopathy due to KasabachMeritt syndrome might cause blood flow disorders of bile duct. But there were no reports of a hemangioma with Kasabach-Merritt syndrome as the cause for biliary stricture and development of obstructive jaundice.

There are some reports that estrogen contributes to hemangioma enlargement [10, 11]. Our case occurred after menopause in the absence of estrogen intake. However, the patient received oral prostaglandin E1, which contains a platelet aggregation inhibitor, to treat spinal canal stenosis and underwent hemodialysis. We suspected that the patient developed Kasabach-Merritt syndrome due to the enlargement of tumor with tendency to bleed.

LHs that are large and symptomatic are usually treated surgically, either by enucleation or by resection. LHs require some form of treatment, such as surgical resection, liver transplantation [12-14], arterial embolization $[15,16]$, interferon $[17,18]$, radiation [19], systemic corticosteroids [20], or radiofrequency ablation [21]. In general, hepatic hemangiomas with Kasabach-Merritt syndrome should be managed by surgical approaches if resection is possible [22]. As there are no reports on the use of transcatheter arterial embolization therapy or bile duct stents in cases where the hemangioma causes biliary stricture, as in this case, surgical resection is currently considered an effective treatment.

\section{Conclusions}

LHs may be enlarged, and those close to the hepatic hilum may potentially compress the bile duct and cause obstructive jaundice. Therefore, there is a need to carefully observe hemangiomas.

\section{Consent}

Written informed consent was obtained from the patient for publication of this case report and any accompanying

Table 1 Reported cases of liver hemangioma causing biliary stricture

\begin{tabular}{|c|c|c|c|c|c|c|c|c|}
\hline Year & First author & Age & Sex & Symptom & Laboratory data & Location & Tumor size & Operation \\
\hline 2008 & Julian E. Losanoff & 42 & $\mathrm{~F}$ & $\begin{array}{l}\text { Discomfort in the right } \\
\text { hypochondrium and itching }\end{array}$ & $\begin{array}{l}\text { T-Bil } 4.2 \mathrm{mg} / \mathrm{dl} \text {, D-Bil } 3.9 \mathrm{mg} / \mathrm{dl} \text {, } \\
\text { ALP } 283 \mathrm{IU} / \mathrm{L}\end{array}$ & Right lobe & $15 \mathrm{~cm}$ & Right hepatectomy \\
\hline 2009 & L Tang & 31 & $\mathrm{~F}$ & Jaundice and amenorrhea & T-Bil 292 mol/l, ALP 575U/l & - & $20 \mathrm{~cm}$ & Right hepatectomy \\
\hline 2015 & Present & 83 & $\mathrm{~F}$ & Itching & $\begin{array}{l}\text { T-Bil } 4.6 \mathrm{mg} / \mathrm{dl} \text {, D-Bil } 3.7 \mathrm{mg} / \mathrm{dl} \text {, } \\
\text { ALP } 1333 \mathrm{IU} / \mathrm{L}\end{array}$ & S4-S5 & $13 \mathrm{~cm}$ & Segmentectomy \\
\hline
\end{tabular}

$T$-Bil total birilubine, $D$-Bil direct birilubine, $A L P$ alkaline phosphatase 
images. A copy of the written consent is available for review by the Editor-in-Chief of this journal.

\section{Abbreviations}

LH: liver hemangioma; T-Bil: total bilirubin; D-Bil: direct bilirubin; ALP: alkaline phosphatase; $\gamma$-GTP: gamma glutamyl transpeptidase; CT: computed tomography; ERCP: endoscopic retrograde cholangiopancreatography; MRI: magnetic resonance imaging

\section{Competing interests}

The authors declare that they have no competing interests.

\section{Authors' contributions}

TY drafted the manuscript. TK treated the patient and helped draft the manuscript. SK helped draft the manuscript. HA treated the patient. HT and $\mathrm{HO}$ determined the treatment plan and revised the manuscript. All authors read and approved the final manuscript.

\section{Authors' information}

TY and SK are staff surgeon in the Department of Gastroenterological and Transplant Surgery, Applied Life Sciences, Institute of Biomedical \& Health Sciences, Hiroshima University. TK and HA are assistant professors in the Department of Gastroenterological and Transplant Surgery, Applied Life Sciences, Institute of Biomedical \& Health Sciences, Hiroshima University. HT is an associate professor in the Department of Gastroenterological and Transplant Surgery, Applied Life Sciences, Institute of Biomedical \& Health Sciences, Hiroshima University. HO is a professor in the Department of Gastroenterological and Transplant Surgery, Applied Life Sciences, Institute of Biomedical \& Health Sciences, Hiroshima University.

\section{Acknowledgements}

We thank Dr Noriyuki Shiroma and Prof Koji Arihiro (Department of Anatomical Pathology, Hiroshima University) for the pathological diagnosis. This case report is not supported by any grants.

Received: 22 April 2015 Accepted: 1 October 2015

Published online: 06 October 2015

\section{References}

1. Ishak KG, Rabin L. Benign tumors of the liver. Med Clin North Am. 1975:59(4):995-1013.

2. Ochsner IL, Halpert B. Cavernous hemangioma of the liver. Surgery. 1958:43(4):577-82.

3. Yoon SS, Charny CK, Fong Y, Jarnagin WR, Schwartz LH, Blumgart LH, et al. Diagnosis, management, and outcomes of 115 patients with hepatic hemangioma. J Am Coll Surg. 2003;197(3):392-402. doi:10.1016/ s1072-7515(03)00420-4.

4. Thomas JH, Pierce GE, Karlin C, Hermreck AS, MacArthur RI. Extrahepatic biliary obstruction secondary to metastatic cancer. Am J Surg. 1981;142(6):770-3.

5. Charles AR, Gupta AK, Bhatnagar V. Giant congenital solitary cyst of the liver: report of a case. Surg Today. 2001;31(8):732-4.

6. Ito K, Taira K, Arii S. Intrahepatic bile duct dilatation with a liver cyst and hemangioma: report of a case. Surg Today. 2009;39(3):256-60. doi:10.1007/ s00595-008-3831-6.

7. Losanoff JE, Millis JM. Liver hemangioma complicated by obstructive jaundice. Am J Surg. 2008;196(3):e3-4. doi:10.1016/j.amjsurg.2007.08.069.

8. Tang L, Zhou WP. Education and imaging. Hepatobiliary and pancreatic: large cavernous hemangioma with obstructive jaundice. J Gastroenterol Hepatol. 2009;24(5):930. doi:10.1111/j.1440-1746.2009.05889.x.

9. Lapeyre M, Mathieu D, Tailboux L, Rahmouni A, Kobeiter H. Dilatation of the intrahepatic bile ducts associated with benign liver lesions: an unusual finding. Eur Radiol. 2002;12(1):71-3. doi:10.1007/s003300100867.

10. Xiao $X$, Hong $L$, Sheng M. Promoting effect of estrogen on the proliferation of hemangioma vascular endothelial cells in vitro. J Pediatr Surg. 1999;34(11):1603-5.

11. Conter RL, Longmire Jr WP. Recurrent hepatic hemangiomas. Possible association with estrogen therapy. Ann Surg. 1988;207(2):115-9.

12. Longeville JH, de la Hall $\mathrm{P}$, Dolan $\mathrm{P}$, Holt AW, Lillie PE, Williams JA, et al. Treatment of a giant haemangioma of the liver with Kasabach-Merritt syndrome by orthotopic liver transplant a case report. HPB Surg. 1997;10(3):159-62.
13. Meguro M, Soejima $Y$, Taketomi A, Ikegami T, Yamashita $Y$, Harada N, et al. Living donor liver transplantation in a patient with giant hepatic hemangioma complicated by Kasabach-Merritt syndrome: report of a case. Surg Today. 2008;38(5):463-8. doi:10.1007/s00595-007-3623-4.

14. Vagefi PA, Klein I, Gelb B, Hameed B, Moff SL, Simko JP, et al. Emergent orthotopic liver transplantation for hemorrhage from a giant cavernous hepatic hemangioma: case report and review. J Gastrointest Surg. 2011;15(1):209-14. doi:10.1007/s11605-010-1248-1.

15. Billio A, Pescosta N, Rosanelli C, Zanon GF, Gamba PG, Savastano S, et al. Treatment of Kasabach-Merritt syndrome by embolisation of a giant liver hemangioma. Am J Hematol. 2001;66(2):140-1. doi:10.1002/ 1096-8652(200102)66:2<140::aid-ajh1031>3.0.co;2-5.

16. Suzuki H, Nimura Y, Kamiya J, Kondo S, Nagino M, Kanai M, et al. Preoperative transcatheter arterial embolization for giant cavernous hemangioma of the liver with consumption coagulopathy. Am J Gastroenterol. 1997;92(4):688-91.

17. Ezekowitz RA, Mulliken JB, Folkman J. Interferon alfa-2a therapy for life-threatening hemangiomas of infancy. N Engl J Med. 1992;326(22):1456-63. doi:10.1056/nejm199205283262203.

18. Nako Y, Fukushima N, Igarashi T, Hoshino M, Sugiyama M, Tomomasa T, et al. Successful interferon therapy in a neonate with life-threatening Kasabach-Merritt syndrome. J Perinatol. 1997;17(3):244-7.

19. Gaspar L, Mascarenhas F, da Costa MS, Dias JS, Afonso JG, Silvestre ME. Radiation therapy in the unresectable cavernous hemangioma of the liver. Radiother Oncol. 1993;29(1):45-50.

20. Takahashi T, Kuwao S, Katagiri H, Kakita A. Multiple liver hemangiomas enlargement during long-term steroid therapy for myasthenia gravis. Dig Dis Sci. 1998;43(7):1553-61.

21. Gao J, Ke S, Ding XM, Zhou YM, Qian XJ, Sun WB. Radiofrequency ablation for large hepatic hemangiomas: initial experience and lessons. Surgery. 2013;153(1):78-85. doi:10.1016/j.surg.2012.06.004.

22. Popescu I, Ciurea S, Brasoveanu V, Hrehoret D, Boeti P, Georgescu S, et al. Liver hemangioma revisited: current surgical indications, technical aspects, results. Hepatogastroenterology. 2001;48(39):770-6.

\section{Submit your manuscript to a SpringerOpen ${ }^{\circ}$ journal and benefit from:}

- Convenient online submission

Rigorous peer review

- Immediate publication on acceptance

- Open access: articles freely available online

- High visibility within the field

- Retaining the copyright to your article

Submit your next manuscript at $\gg$ springeropen.com 